\title{
Diagnóstico das condições higiênico-sanitárias em queijarias: uma revisão
}

\author{
Diagnostic of hygienic sanitary conditions in cheeses factories: a review \\ Diagnóstico de las condiciones higiénicas sanitárias en las queserías: uma revisión
}

Recebido: 07/01/2021 | Revisado: 11/02/2021 | Aceito: 22/02/2021 | Publicado: 28/02/2021

\author{
Jessica do Vale Simas \\ ORCID: https://orcid.org/0000-0002-1372-496X \\ Universidade de Vassouras, Brasil \\ E-mail: jeh_simas@hotmail.com \\ Gabriela Vieira do Amaral \\ ORCID: https://orcid.org/0000-0003-3817-8122 \\ Universidade de Vassouras, Brasil \\ E-mail: gabriela.vda@hotmail.com \\ Damaris Alves dos Santos \\ ORCID: https://orcid.org/0000-0001-7516-6871 \\ Universidade de Vassouras, Brasil \\ E-mail: damarisvet@hotmail.com
}

\begin{abstract}
Resumo
Os queijos fabricados de forma artesanal podem apresentar uma maior probabilidade de contaminação se forem produzidos com matérias-primas qua não são seguras. Por isso, é importante que as empresas adotem a implementação de Programas de Controle de fabricação e qualidade, para que assim diminua os riscos de contaminação, além de assegurar que ele seja produzido com matéria-prima de qualidade e o processo siga todas as normas vigentes para que se tenha um produto final seguro. Pensando nisso, esta pesquisa teve como finalidade copreender o controle de qualidade e fabricação de queijos, mediante uma revisão bibliográfica. Foram comparados 5 artigos nacionais relacionados às condições higiênico-sanitárias de queijarias em bases de dados como Scielo, PubVet, Portal Legislativo do Ministério da Agricultura, Pecuária e Abastecimento (MAPA), site da Agência Nacional de Vigilância Sanitária (ANVISA) e no Portal da Embrapa e em livros publicados, entre os anos de 2010 e 2020 . Essa comparação mostrou que os estabelecimentos, na maioria não possuia quaquer tipo de fiscalização e não executavam as atividades de acordo com a legislação vigente. Com isso, pode-se constatar, que os queijos produzidos eram de baixa qualidade.
\end{abstract}

Palavras-chave: Autocontrole; Check list; Queijos.

\begin{abstract}
Cheeses manufactured by hand may be more likely to be contaminate if they are produced with raw materials that are not safe. For this reason, it is important that companies adopt the implementation of manufacturing and quality control programs, so that the risk of contamination is reduced, in addition to ensuring that it is produced with quality raw material and the process follows all current regulations to have a safe final product. With this in mind, this research aimed to understand the quality control and cheese making, through a bibliographic review. Five national articles related to the hygienic-sanitary conditions of cheesemakers were compared in databases such as Scielo, Pub Vet, Legislative Portal of Ministry of Agriculture, Livestock and Supply, website of the Nacional Health Surveillance Agency and the Portal da Embrapa and in published books, between the years 2010 and 2020. This comparison, showed that most establishments did not have any type of inspection and did not carry out activities in accordance with current legislation. Thus, it can be seen that the cheeses produced were of low quality.
\end{abstract}

Keywords: Self control; Check list; Cheeses.

\section{Resumen}

Es más probable que los quesos fabricados a mano se contaminen si se producen com matérias primas que no son seguras. Por este motivo, es importante que las empresas adopten la implementación de programas de fabricación y control de calidad, de manera que se reduzca el riesgo de contaminación, además, de assegurar que se produce com materia prima de calidad y el processo sigue todas las normativas vigentes, para tener um produto final seguro. Com esto em mente, esta investigación tuvo como objetivo compreender el control de calidad y la elaboración del queso, a través de uma revisión bibliográfica. Se compararon cinco artículos nacionales relacionados com las condiciones higénico-sanitarias de los queseros em bases de datos como Scielo, Pub Vet, Portal Legislativo del Ministerio de Agricultura, Ganadería y Abastecimento, web de la Agencia Nacional de Vigilancia Sanitaria y el Portal Embrapa y en libros publicados, entre los años de 2010 y 2020. Com esta comparativa se puede apreciar que los establecimientos, 
em su mayoría, no cuentan com ningún tipo de fiscalización y no realizan atividades de acuerdo com la legislación vigente. Así, se puede apreciar que los quesos elaborados son de baja calidad.

Palabras clave: Autocontrol; Lista de verificacíon; Quesos.

\section{Introdução}

As últimas informações disponíveis sobre a produção nacional de queijos é de 2019 com volume estimado em 775 mil (setecentos e setenta e cinco mil) toneladas, tendo um aumento de 1,97\% comparado ao ano de 2018, com expectativa de encerramento de 2020 com alta de $2 \%$ (USDA, 2019). O aumento é atribuído a uma maior demanda do consumo doméstico especialmente por parte das indústrias de alimentos. No varejo os dados são otimistas, pois o consumo de leite e derivados cresceu ao longo da pandeia do COVID-19 no Brasil, o que muitos pesquisadores relatam associação do fato com a saudabilidade (CILeite, 2020). Uma pesquisa recente da Embrapa, mostrou que o queijo é o derivado lácteo mais adquirido, e diferente do que aconteceu em outros países, no Brasil, a grande maioria dos consumidores (83\%) está encontrando com facilidade os produtos lácteos no mercado, o que reflete o comprometimento dos produtores e laticínios em manter o abastecimento (EMBRAPA, 2020).

Existe uma variedade de tipos de queijos no Brasil, mas de maneira geral os todos passam pelo mesmo tipo de processamento inicial, e são denominados como o produto lácteo fresco ou maturado que se obtém por meio da separação parcial do soro em relação ao leite ou ao leite reconstituído - integral, parcial ou totalmente desnatado - ou de soros lácteos, coagulados pela ação do coalho, de enzimas específicas, produzidas por microrganismos específicos, de ácidos orgânicos, isolados ou combinados, todos de qualidade apta para uso alimentar, com ou sem adição de substâncias alimentícias, de especiarias, de condimentos ou de aditivos (Brasil, 2017).

São produtos altamente manipulado, por isso de fácil contaminação desde a sua obtenção ao seu preparo (Ferreira et al, 2011). A garantia de qualidade sanitária de produtos alimentícios faz parte da preocupação dos profissionais envolvidos com o preparo de alimentos. A excelência em qualidade, na fabricação dos produtos, confere credibilidade a uma empresa, à medida que os esforços estão voltados para garantia da saúde do consumidor.

Neste contexto, é importante identificar as condições em que os queijos são produzidos no país. Portanto, devido ao exposto, este estudo teve como objetivo de reunir, em uma revisão bibliográfica, artigos nacionais, publicados nos últimos 10 anos, com foco na identificação das condições higiênico sanitárias em queijarias.

\section{Metodologia}

Para a pesquisa bibliográfica, foram consultadas as principais bases de dados nacionais, bem como as legislações vigentes. Foram reunidos 19 documentos sobre a temática, destes, 5 autores utilizaram o método do checklist como ferramenta de verificação das condições higiênico sanitárias, como exposto na Tabela 1. Este é um trabalho de natureza qualitativa e foi baseado no trabalho de Francisco Regis da Silva et al (2017).

O checklist é uma lista de verificação que tem como objetivo através de uma análise observacional analisar as condições higiênico-sanitárias de estabelecimentos produtores e industrializadores de alimentos informando pontos de conformidades e não conformidades. Assim, visando instituir adequações pela identificação de pontos críticos em instalações e processos produtivos, a fim de eliminar ou reduzir riscos de contaminações físicas, químicas e biológicas (ANVISA, 2002).

Dos trabalhos pesquisados, três (3) elaboraram o checklist baseados na RDC n ${ }^{\circ} 275$ de 21 de outubro de 2002, um (1) elaborou o checklist baseado no trabalho de Pinto (2004) e 1 elaborou baseado na portaria no 326 de 30 de julho de 1997. 
Tabela 1. Verificação das condições higiênico sanitárias em propriedades produtoras de queijo.

\begin{tabular}{ll}
\hline $\begin{array}{l}\text { Autor, } \\
\text { ano }\end{array}$ & \multicolumn{1}{c}{ Metodologia } \\
\hline Mera et & 10 estabelecimentos avaliados \\
al & através de checklist da RDC \\
$(2020)$ & $275 / 2002$. Estudo realizado em \\
& Municípios do Rio Grande do \\
& Sul
\end{tabular}
Sul

Resultados
Em $20 \%$ dos estabelecimentos havia foco de poeira, objetos em desuso e transito de animais. As instalações
estruturais estavam de acordo em $80 \%$. Somente dois estabelecimentos utilizavam mobiliário de madeiras
em algumas etapas da produção, as demais apresentavam mobiliário adequado. Em $80 \%$ os utensílios não
possuíam um local certo para armazenamento. Em todos os estabelecimentos os colaboradores haviam
passado por treinamentos em boas práticas de manipulação e em $60 \%$ os colaboradores estavam
adequadamente uniformizados. Apenas $10 \%$ possuíam planilhas de controle de qualidade e $90 \%$ não são
inspecionavam a recepção de matérias primas. Em $90 \%$ os produtos finais estavam acondicionados em
embalagens adequadas e integras, e veículos transportadores em boas condições. A maioria das queijarias
apresentavam um bom percentual de conformidades, tendo consequentemente um produto de melhor
qualidade.
qualidade.

Oliveira 8 estabelecimentos artesanais et al avaliados através de checklist (2018) da RDC 275/2002. Estudo realizado no Sertão Paraibano

\begin{tabular}{ll}
\hline Santos & 15 estabelecimentos avaliados \\
et al & através do checklist de Pinto \\
(2017) & (2004). Estudo realizado em \\
& Uberaba, MG
\end{tabular}

Em duas queijarias as conformidades estavam em 58,4\% e 75,8\% respectivamente. Já em outras duas queijarias as não conformidades foram de $91,1 \%$ e $93,8 \%$ respectivamente, onde o terreno não havia pavimentação, os pisos estavam malconservados e quebrados, janelas com tela de proteção rasgada e lâmpadas sem proteção e tetos e paredes com infiltrações e bolores. Duas queijarias com 89,5\% e 100\%, de não conformidades nos itens de equipamentos, móveis e utensílios, além da precariedade na limpeza e sanitização. Constante uso de material de madeira, como colheres, formas e prensas. $100 \%$ das queijarias tiveram altos índices de não conformidades na higiene dos manipuladores, duas com quase $90 \%$ de não conformidades. Quatro queijarias obtiveram maiores índices de não conformidades em relação ao transporte e produção, foram encontradas falhas na recepção de matéria-prima. 100\% das queijarias não realizavam tratamento térmico. E 100\% das queijarias não possuíam o Manual de BPF. As queijarias apresentavam um baixo nível de conformidades, apresentando muitos problemas que interferem na qualidade final do produto. Em $60 \%$ das propriedades o queijo era produzido nas cozinhas das residências, $13 \%$ no próprio curral e $27 \%$ possuíam instalações estruturais inadequadas. Em $100 \%$ das propriedades a água não era clorada e em $47 \%$ a fonte de água vinha do poço artesiano. Cerca de 70\% faziam uso de utensílios inadequados. Em 40\% era realizado exames de saúde periódicos nos colaboradores. $67 \%$ dos produtores realizavam pré-lavagem de todos os materiais e utensílios da produção, mas não seguiam procedimentos de higienização. Animais domésticos nas adjacências da produção em $93 \%$ dos estabelecimentos. Afirmando assim, que os queijos produzidos eram de baixa qualidade e provenientes de uma série de falhas higiênicas de processo e produção.

Em cinco estabelecimentos não possuíam local exclusivo para fabricação e utilizavam a própria cozinha da residência. Uso do leite cru foi observado em três estabelecimentos. Apenas uma apresentou adequação ao local de fabricação. 100\% dos estabelecimentos não apresentaram manual de BPF. Três estabelecimentos tiveram percentual de $70 \%$, $82 \%$ e $85 \%$ de conformidade em relação ao manejo dos resíduos. Manipuladores, $100 \%$ não obteve bons resultados, e um estabelecimento teve apenas $21 \%$ de atendimento das conformidades. Controle integrado de pragas, apenas um estabelecimento atendia a $50 \%$ dos requisitos, os outros atendiam $0 \%$. Todos os estabelecimentos foram classificados como ruins e produziam queijos de baixa qualidade
Estrutura física livre de focos de insalubridade, sem objetos em desuso e transito de animais. Pisos, paredes, portas e janelas estavam bons. Todos esses itens atendiam as exigências. Higienização dos equipamentos era realizada após o termino da produção e feita com água oxigenada e o enxágue com água em abundância e não eram esfregados os equipamentos. O leite era recebido na parte da manhã em latões, eram realizadas analises de acides, crioscopia, densidade e porcentagem de gordura. Transporte do leite não era feito em caminhão isotérmico. Com a implantação da BPF houve uma melhora das condições higiênico-sanitárias.

\begin{tabular}{lll}
\cline { 2 - 3 } $\begin{array}{l}\text { Ferreira } \\
\text { et al }\end{array}$ & $\begin{array}{l}\text { 1 estabelecimento avaliado } \\
\text { através do checklist da Portaria }\end{array}$ & $\begin{array}{l}\text { Estrutura física livre de focos de insalubridade, sem objetos em desuso e transito de animais. Pisos, paredes, } \\
\text { portas e janelas estavam bons. Todos esses itens atendiam as exigências. Higienização dos equipamentos era } \\
\text { (2011) }\end{array} \mathrm{n}^{\circ} 326 / 1997$ \\
& $\begin{array}{l}\text { realizada após o termino da produção e feita com água oxigenada e o enxágue com água em abundância e } \\
\text { não eram esfregados os equipamentos. O leite era recebido na parte da manhã em latões, eram realizadas } \\
\text { analises de acides, crioscopia, densidade e porcentagem de gordura. Transporte do leite não era feito em } \\
\text { caminhão isotérmico. Com a implantação da BPF houve uma melhora das condições higiênico-sanitárias. }\end{array}$ \\
\hline
\end{tabular}

Ferreira 1 estabelecimento avaliado et al através do checklist da Portaria Fonte: Autores.

A partir dos trabalhos apontados na Tabela 1, evidenciamos que a utilização do checklist foi importante para diagnosticar as condições de manipulação de alimentos nos estabelecimentos visitados. Pois de um modo objetivo as instalações podem ser classificadas em adequadas ou não e as não conformidades podem ser listadas para as adequações necessárias. Dessa forma, foi possível notar a maioria dos locais possuíam condições inadequadas de processamento de queijos. A seguir serão discorridos aspectos importantes com relação aos achados e as necessidades de adequações das não conformidades. 


\section{Resultados e Discussão}

\section{Parâmetros regulatórios}

As condições higiênicas sanitárias em estabelecimentos manipuladores de alimentos são regulamentadas por diversas diretrizes. Desde 2005, para aprimorar os recursos de inspeção, baseado no proposto que o respectivo estabelecimento é responsável por assegurar a qualidade do produto o Departamento de Inspeção de Produtos de Origem Animal (DIPOA) criou os Programas de Autocontrole (PAC).

Muitas são as semelhanças entre o PAC e os programas de pré-requisitos Boas Práticas de Fabricação (BPF), Análises de Pontos Críticos de Controle (APPCC), Procedimentos Padrão de Higiene Operacional (PPHO), no entanto, esta modernização baseou-se fundamentalmente na inspeção contínua e sistemática de todos os fatores que podem interferir na qualidade higiênico-sanitária do produto final (BRASIL, 2005). Os PAC são procedimentos descritos, desenvolvidos, implantados, monitorados e verificados pelo estabelecimento, com vistas a assegurar a inocuidade, a identidade, a qualidade e a integridade dos seus produtos, que incluam, mas que não se limitem aos programas de pré-requisitos, ou a programas equivalentes reconhecidos pelo Ministério da Agricultura, pecuária e Abastecimento (MAPA) (BRASIL, 2020).

Existem algumas legislações que norteiam a implementação dos PAC. São elas: Portaria do MAPA n 368/1997 Regulamento Técnico sobre as Condições Higiênico-Sanitárias e de Boas Práticas de Fabricação para estabelecimentos Elaboradores Industrializadores de Alimentos; Portaria do MAPA n 46/1998 - Estabelece obrigatoriedade de implantação de Sistema de Análise de Perigos e Pontos Críticos de Controle nos estabelecimentos com SIF; RIISPOA Decreto 9013/2017 Regulamento de inspeção industrial e sanitária de produtos de origem animal (MAPA, 2020).

Com o Programa de Autocontrole serão submetidos ao monitoramento: Manutenção; Águas de abastecimento; Controle integrado de pragas; Higiene industrial e operacional; Procedimentos Sanitários Operacionais (PSO) - contaminação cruzada; Controle da matéria-prima, ingredientes e material de embalagem; Controle de Temperaturas; APPCC - Avaliação do Programa de Análise de Perigos e Pontos Críticos de Controle; Análises laboratoriais (microbiológicas e físico-química); Controle de formulação dos produtos e combate à fraude; Rastreabilidade e recolhimento; Respaldo para certificação oficial (Brasil, 2017).

E em 2018 foi criado o Plano de Qualificação de Fornecedores de Leite (PQFL), instituído pela Instrução Normativa $n^{\circ} 77$, uma ferramenta de controle elaborada pela empresa ou cooperativa. Nela é definida a política do laticínio em relação aos seus fornecedores de leite, devendo-se contemplar a assistência técnica e gerencial, bem como a capacitação de todos os produtores, com foco em gestão da propriedade e implementação das boas práticas agropecuárias (BRASIL, 2018a). É um processo continuo e evolutivo onde os esforços dos executores visam qualificar ininterruptamente os fornecedores de leite, melhorando ou aprimorando as Boas Práticas Agropecuárias nos sistemas produtivos, tendo como referência dados estatísticos de controle da matéria-prima e relatórios de acompanhamento da propriedade (MAPA, 2019). Esse Plano se torna obrigatório para os três níveis de inspeções: Serviço de Inspeção Municipal (SIM), Serviço de Inspeção Federal (SIF) e Coordenadoria de Inspeção de Produtos de Origem Animal (CISPOA) (ABIQ, 2020).

O Decreto $\mathrm{n}^{\mathrm{o}} 10.468$ de 18 de agosto de 2020, descreve queijaria como o estabelecimento destinado a fabricação de queijos, que envolva as etapas de fabricação, maturação, acondicionamento, rotulagem, armazenamento e expedição, e que, caso não realize o processamento completo do queijo, encaminhe o produto a uma unidade de beneficiamento de leite e derivados (Brasil, 2020).

Nos trabalhos pesquisados, inclusive expostos na tabela 1, podemos destacar que as piores condições de manipulação foram observadas em produtores artesanais, dos quais, muitas são clandestinos e não possuíam local próprios para manipulação de alimentos. Cabe lembrar, que os produtos de origem animal produzido de maneira artesanal, estão regulamentados desde 
2018 com a Lei 13.680, o Decreto 9.918 de 2019, e a Lei 13.860 de 2019 (Brasil, 2018 e 2019), e que de modo geral a utilização do Selo Arte não substitui os sistemas de fiscalização do Ministério da Agricultura.

\section{Edificações e instalações}

Santos et al (2017) ao avaliarem as condições higiênico sanitárias em 15 queijarias no município de Uberaba/MG, detectaram que em $60 \%$ delas, os queijos eram produzidos nas cozinhas das residências e em $13 \%$ eram produzidos nos currais. Outro estudo, também em Minas Gerais, no município de Viçosa, Vinha et al (2016), também encontrou em 5 agroindústrias familiares onde a fabricação dos queijos eram realizadas nas cozinhas das próprias residências, algumas em condições precárias de higiene, e em somente 1 possuía local exclusivo para a produção.

Os estabelecimentos clandestinos processadores de queijos, ainda são uma realidade nos pequenos municípios do interior, onde a maioria acaba sendo de administração familiar. Mas, independentemente disso, toda empresa do ramo alimentício tem como responsabilidade a qualidade de seus produtos e devem ser registradas e fiscalizadas pelos órgãos competentes (Oliveira et al, 2018), que podem ser as Secretárias de Inspeção Municipais, Estaduais ou Federais, o Ministério da Agricultura, Pecuária e Abastecimento (MAPA) e devem ser registrados no Departamento de Inspeção de Produtos de Origem Animal (DIPOA) para que a comercialização seja feita dentro do que foi estabelecido (Brasil,2017).

Em contrapartida, Ferreira et al. (2011), também em Minas Gerais, encontrou em um laticínio localizado em Piumhi, uma estrutura livre de focos de insalubridade, livre de odores, sem objetos em desuso e sem trânsito de animais, com acesso independente para a instalação. Pisos e paredes lisos e resistentes, laváveis e de cores claras. Portas identificadas e de vidro, janelas de vidro e com tela de proteção contra pragas, apesar da tela estar fora do nível da parede, o que pode gerar um acumulo de sujidades. As lâmpadas eram protegidas, um local bem iluminado e arejado.

Recentemente em municípios do Rio grande do Sul, Mera e colaboradores (2020), encontraram nos estabelecimentos pesquisados, que as edificações e instalações foi o grupo com maiores inadequações. Das 10 unidades avaliadas, 20\% retratavam foco de poeira, objetos em desuso, não possuíam sistema de drenagem eficiente com o tamanho das instalações, e ausência de ralos que impedissem a entrada de pragas em $70 \%$ dos estabelecimentos. Os pisos já apresentavam adequações, lisos, impermeáveis e de fácil limpeza, e as paredes estavam dentro das especificações em $80 \%$ dos estabelecimentos, já os tetos em $90 \%$ não eram abaulados dificultando a limpeza.

A legislação é clara em relação ao local de produção de queijos, e diz que ele deve ser livre de focos de insalubridade, livre de objetos em desuso ou estranhos ao ambiente, livre de focos de poeira, acumulo de lixo e água estagnada, ter frequência de higienização das instalações adequadas e o acesso deve ser direto e não comum a outros usos, como habitação (ANVISA, 2002). Pisos, paredes e tetos devem ser de cor clara, material de fácil limpeza e livres de rachaduras, trincas, buracos, de material resistente e com declive, para evitar acumulo de sujidades. As portas devem ter fechamento automático e com barreiras para impedir entrada de vetores, livres de rachaduras, umidade ou descascando (ANVISA, 2002).

Alguns estudos relataram a falta de cerca e transito de animais domésticos como cães e gatos nas adjacências, inclusive em locais de processamento (Mera et al., 2020; Santos et al., 2017). Cabe lembrar que os locais devem ser livres de vetores e outros animais no pátio e vizinhança, além disso as janelas também não podem ter falhas de revestimento e devem ter proteção como telas milimétricas contra insetos e roedores (ANVISA, 2002).

Santos et al (2017) encontrou em todas as propriedades a água de consumo em caixas de água, mas a cloração não era feita, e em $47 \%$ dos estabelecimentos, possuíam como fonte de água o poço artesiano. Foi o mesmo que Ferreira e colaboradores (2011) encontrou em Piumhi, Minas Gerais, a água que era utilizada na queijaria era proveniente de poço artesiano localizado na propriedade, neste caso, a água foi considerada de boa qualidade. Oliveira (2018), também encontrou 
queijarias onde a água era proveniente de poços e cisternas e não eram submetidas a análise laboratorial para verificar sua potabilidade.

$\mathrm{Na}$ legislação o reservatório de água deve ser acessível, com instalação hidráulica com volume, pressão e temperatura adequados, dotados de tampas, em satisfatória condição de uso, livre de vazamentos, infiltrações e descascamento. Também é importante a existência de responsável comprovadamente capacitado para a higienização do reservatório de água, apropriada frequência de higienização desse reservatório, com comprovada existência de registro da higienização desse reservatório (ANVISA, 2002). Ainda, a potabilidade da agua deve ser testada por meio de laudos laboratoriais, com adequada periodicidade, assinados por técnico responsável pela análise ou expedidos por empresas terceirizadas (ANVISA, 2002).

\section{Equipamentos, Utensílios e Móveis}

Em relação aos utensílios e móveis utilizados na produção, Santos et al (2017), encontrou em 33\% dos produtores apenas faziam uso das peneiras de plástico, e $69 \%$ dos produtores realizavam a coagulação do leite em tambores plásticos não apropriados. Na agitação da massa, $40 \%$ dos manipuladores utilizavam espátula de madeira, o que não é permitido pela lei. Mera et al (2020), ao analisar agroindústrias familiares em municípios do Rio Grande do Sul, dentro de 10 propriedades, em 90\% os utensílios estavam de forma a permitir fácil acesso a higienização adequada, em 100\% apresentavam mobiliário adequado, que devem ser lisos, impermeáveis, resistentes e de preferência de aço inoxidável, porém, em duas propriedades ainda eram utilizados móveis em madeira, e em $80 \%$ não possuíam um local adequado de armazenamento para os utensílios. Isso também foi o que Oliveira (2018) encontrou em queijarias localizadas no sertão Paraibano. Entre 8 queijarias, duas apresentaram os piores índices de não conformidades com 89,5\% e 100\% respectivamente, em relação ao material e estado de conservação dos utensílios. Foram encontradas precariedades na limpeza dos utensílios, encontrando acúmulo de resíduos de massa de queijos, além de utilizarem prensas, formas e colheres de madeira.

Segundo a legislação, as mesas e bancadas devem ser em número suficiente, em adequado estado de conservação, impermeáveis, de maneira que permita uma fácil higienização, com material não contaminante e que resista à corrosão. Os utensílios devem ser armazenados em locais apropriados, protegidos contra contaminação e organizados, devem ser higienizados frequentemente por uma pessoa responsável e capacitada.

\section{Manipuladores}

Item muito importante, que deve receber atenção é em relação a saúde dos manipuladores, já que são eles que participam do processo de fabricação do início ao fim. Nesse item é importante avaliar se os manipuladores estão utilizando uniformes limpos e de cores claras, se fazem a lavagem cuidadosa das mãos, principalmente após qualquer interrupção e depois do uso de sanitários, se são colocados cartazes com orientações sobre a correta higiene das mãos e dos demais hábitos. Importante verificar se estão livres de afecções cutâneas, feridas e supurações, e com ausência de sintomas de infecções respiratórias, gastrointestinais e oculares, além do uso individual de equipamentos de proteção (EPI) (ANVISA, 2002).

Com isso, Oliveira (2018), encontrou, os piores índices de conformidades, com 90\% dos manipuladores que não faziam a higiene correta das mãos, e não utilizavam uniformes limpos, além de utilizarem adornos (brincos, alianças e relógios).

Além disso os colaboradores precisam passar por treinamentos frequentes, para entender mais a respeito dos perigos associados a manipulação dos alimentos, bem como sobre as doenças transmissíveis por alimentos (DTA). O responsável pelas atividades de manipulação dos alimentos deve ser comprovadamente submetido a curso de capacitação, abordando, no mínimo, os temas de contaminantes alimentares, Doenças transmitidas por alimentos, Manipulação higiênica dos alimentos e Boas Práticas (ANVISA, 2004). 


\section{Produção e transporte do alimento}

O leite é um alimento que se não conservado em temperatura adequada e manipulado de forma correta se contamina muito fácil. A recente atualização do RIISPOA (Brasil, 2020) estabelece as temperaturas adequadas para a manutenção, transporte e recepção do leite cru, que foram alteradas para $5^{\circ} \mathrm{C}$ (cinco graus Celsius) a temperatura de conservação do leite no posto de refrigeração na unidade de beneficiamento e na câmara frigorifica do leite pasteurizado a temperatura pode atingir até $7^{\circ} \mathrm{C}$ (sete graus Celsius), quando o leite estocado apresenta contagem microbiológica máxima de $300.000 \mathrm{UFC} / \mathrm{mL}$ anteriormente ao beneficiamento.

Os derivados lácteos também devem ser manipulados da forma mais cuidadosa possível, respeitando temperatura e higiene do local de processamento, como estipula o RIISPOA (Brasil, 2020) que deve ser de até $5^{\circ} \mathrm{C}$ (cinco graus Celsius). Com isso, a legislação estabelece que a recepção da matéria-prima, ingredientes e embalagens devem ser realizadas em local protegido e isolado da área de processamento, devem ser inspecionados na recepção, controlar com planilhas a temperatura e características sensoriais e as condições de transportes (ANVISA, 2002).

Alguns dos estabelecimentos investigados relataram que o beneficiamento de queijos se dava a partir do leite cru (Oliveira et al, 2018; Vinha et al, 2016), no entanto, o processamento térmico do leite é uma etapa de fundamental importância para assegurar a inativação e bactérias patogênicas. A legislação vigente estabelece que o leite destinado para a fabricação de queijos passe por pasteurização lenta $\left(62^{\circ} \mathrm{C}\right.$ a $65^{\circ} \mathrm{C}$ durante 30 minutos) ou pasteurização rápida $\left(72^{\circ} \mathrm{C}\right.$ a $75^{\circ} \mathrm{C}$ durante 15 a 20 segundos) (Brasil, 2017).

$\mathrm{O}$ tratamento térmico do leite somente fica excluído da obrigação quando esse leite se destina à elaboração de queijos maturados, neste caso o processo deve ser a uma temperatura não inferior a $5^{\circ} \mathrm{C}$, num período de pelo menos 60 dias (BRASIL, 2020). Além disso, algumas regiões, como o Estado de Minas Gerais podem produzir queijos artesanais a partir do leite cru, desde que ele tenha um período de maturação de pelo menos 60 dias (sessenta dias), e as propriedades devem ser livre de focos de Tuberculose e Brucelose, além é claro de implementar BPF, ter o controle de pragas e transporte adequado do produto até o entreposto (Brasil, 2018).

Verificar se os rótulos das matérias-primas e ingredientes atendem a legislação e se são armazenados em locais adequados e organizados. Os locais de pré-preparo, chamada de área suja, deve ser isolado da área de preparo e ter controle de circulação de pessoas. Nas embalagens do produto final é importante a identificação de acordo com a legislação vigente, produto final em embalagens adequadas e integras, a rede de frio adequada ao volume e aos diferentes tipos de alimentos, ter um controle de qualidade do produto final. Além do mais, o produto tem que ser transportado em temperatura especificada no rótulo, em veículos limpos e com ausência de vetores e pragas e não podendo transportar outras cargas que comprometam a segurança do produto (ANVISA, 2002).

Os rótulos devem ser resistentes às condições de armazenamento e de transporte do produto, devem possuir identificação que permita a rastreabilidade, informações visíveis e legíveis e devem conter de forma clara e legível: o nome, nome da empresa e endereço do estabelecimento produtor, carimbo do Órgão que regulamenta (SIE, SIM ou SIF), CNPJ ou $\mathrm{CPF}$, marca comercial quando houver, data de fabricação, prazo de validade e identificação do lote, lista de ingredientes e aditivos, indicação do número de registro do produto no DIPOA, identificação do país de origem, instruções sobre a conservação e instruções sobre preparo e uso quando necessário (Brasil, 2017).

Contradizendo isto, Oliveira (2018), encontrou duas queijarias em seu estudo que obtiveram os maiores índices de não conformidades, já que na recepção do leite foram encontradas falhas na verificação da qualidade da matéria-prima, o tempo de recepção do leite era superior a 2 horas, e era transportado em recipientes não recomendados, como tambores plásticos reaproveitados de outros produtos ou em garrafas pet sem qualquer refrigeração. 
Mera et al (2020), verificou que em 90\% dos estabelecimentos as matérias-primas não eram inspecionadas na recepção, apenas $10 \%$ tinham uma planilha com controle indicando características sensoriais e temperatura. Já as embalagens do produto final, $90 \%$ estavam acondicionados em embalagens integras e adequadas, mas, em $80 \%$ os produtos não eram transportados na temperatura especificada no rótulo. No veículo em que eram transportados os queijos, em 90\% não foram encontrados qualquer tipo de vetores ou pragas urbanas ou indícios de existirem (Mera et al., 2020).

\section{Documentação}

O manual das BPF, avalia se as operações executadas no estabelecimento estão de acordo e se os procedimentos operacionais padronizados estão sendo cumpridos. Como avaliação do controle de potabilidade da água, higiene dos manipuladores, manejo dos resíduos, manutenção dos equipamentos, controle de vetores e pragas urbanas, análise e seleção das matérias-primas, ingrediente e embalagens (ANVISA, 2002).

Porém, na maioria das queijarias/ agroindústrias pesquisadas pelos autores, não foi possível encontrar essa documentação. Alguns produtores tinham conhecimento do Manual das BPF, mas não o deixavam disponíveis nos locais, como foi citado por Mera et al (2010), em que o manual ficava sobre responsabilidade e execução de empresa terceirizada que atuavam no controle da potabilidade da água e no controle integrado de pragas e vetores. Os outros estabelecimentos simplesmente não faziam uso ou não obtinham o conhecimento.

No PAC, quatro tipos de registros devem ser mantidos como parte do programa de autocontrole. São eles: Documentação de apoio para desenvolvimento do programa, Registros gerados pela aplicação do programa, Documentação de métodos e procedimentos usados e Registros de programas de treinamentos dos funcionários. As revisões dos registros devem ser realizadas na empresa por pessoal qualificado ou por autoridades externas, como consultores para assegurar o comprimento rígido dos critérios estabelecidos (Brasil, 2020).

\section{Considerações Finais}

Como o leite é um produto perecível e de fácil contaminação, é essencial que desde a ordenha até o consumidor final os processos sejam controlados para evitar a contaminação.

Foi visto nessa pesquisa, que em todas as queijarias, mesmos as que possuíam algum tipo de fiscalização, deixaram de cumprir algum requisito importante no processo de fabricação, fazendo com que todas as queijarias tenham tido uma avaliação ruim em relação as condições higiênicas sanitárias. No entanto, é de fundamental importância manter as condições higiênicosanitárias no processamento de queijos, para se obter um produto final de qualidade sem oferecer riscos aos consumidores.

Muitos estudos ainda apontam que existem locais com péssimo processamento de queijos, e muito ainda deve ser feito para a regularização dos estabelecimentos. Assim, com uma implementação da cultura de segurança de alimentos, se tornando parte dos estabelecimentos e parte do treinamento dos colaboradores, é possível que cada vez mais estabelecimentos considerados artesanais, consigam produzir em ambientes considerados seguros.

\section{Referências}

ABIQ (2020). Associação Brasileira das Indústrias de Queijo. Novo prazo para entrega PQFL é 31 de dezembro e contempla práticas emergenciais nos estabelecimentos. Brasil, 2020.

Brasil (1997). Portaria no 368 de 08 de setembro de 1997. Aprova o regulamento técnico sobre condições higiênico sanitárias e de boas práticas de fabricação para estabelecimentos produtores/industrializadores de alimentos. Ministério da Agricultura, Pecuária e Abastecimento, Diário Oficial da República Federativa do Brasil, 1997.

Brasil (2004). Resolução RDC no 216 de 15 de setembro de 2004. Dispões sobre Regulamento Técnico de Boas Práticas para Serviços de Alimentos. Agencia Nacional de Vigilância Sanitária (ANVISA). Brasil, 2004. 
Research, Society and Development, v. 10, n. 2, e57610211770, 2021

(CC BY 4.0) | ISSN 2525-3409 | DOI: http://dx.doi.org/10.33448/rsd-v10i2.11770

Brasil (2002). Resolução RDC no 275 de 21 de outubro de 2002. Aprova o regulamento Técnico de Procedimentos Operacionais Padronizados aplicados aos Estabelecimentos Produtores/Industrializadores de Alimentos e a Lista de Verificação das Boas Práticas de Fabricação em Estabelecimentos Produtores/Industrializadores de Alimentos. Agência Nacional de Vigilância Sanitária (ANVISA), Brasil, 2002.

Brasil (2018). Instrução Normativa ${ }^{\circ} 77$ de 26 de novembro de 2018. Ficam estabelecidos os critérios e procedimentos para a produção, acondicionamento, conservação, transporte, seleção e recepção do leite cru em estabelecimentos registrados no serviço de inspeção oficial, na forma desta Instrução Normativa e do seu Anexo. Ministério da Agricultura, Pecuária e Abastecimento (MAPA), Brasil, 2018.

Brasil (2018). Lei $\mathrm{n}^{\circ} 13.680$ de 14 de junho de 2018. Altera a Lei $n^{\circ} 1.283$ de 18 de dezembro de 1950, para dispor sobre o processo de fiscalização de produtos alimentícios de origem animal produzidos de forma artesanal. Senado Federal. Secretaria - Geral da Mesa. Secretara de Informação Legislativa. Brasil, 2018.

Brasil (2019). Plano de Qualificação de Fornecedores de Leite - PQFL. Ministério da Agricultura, Pecuária e Abastecimento (MAPA). Brasil, 2019.

Brasil (2019). Lei $\mathrm{n}^{\circ} 13.860$ de 18 de julho de 2019. Dispõe sobre a elaboração e a comercialização de queijos artesanais e dá outras providências. Presidência da República. Secretária - Geral. Subchefia para Assuntos Jurídicos. Brasil, 2019.

Brasil (2019). Decreto $\mathrm{n}^{\circ} 9.918$ de 18 de julho de 2019. Regulamenta o art. 10-A da Lei $n^{\circ} 1.283$ de 18 de dezembro de 1950, que dispõe sobre o processo de fiscalização de produtos alimentícios de origem animal produzidos de forma artesanal. Diário Oficial da União. Brasil, 2019.

Brasil (2020). Verificação Oficial de Elementos de Controle. Ministério da Agricultura, Pecuária e Abastecimento (MAPA). Brasil, 2020.

Embrapa (2020). Pandemia provoca mudança de hábitos de consumo de produtos lácteos, aponta pesquisa. Brasil, 2020.

Ferreira, F. S., Moura, M. S., \& Silveira, A. C. P. (2011). Implantação de Boas Práticas de Fabricação (BPF) em um laticínio de Piumhi-MG. Revista PubVet, Londrina, 5(13), 160, Art. 1082, 2011.

Mera, C. M. P., Menegazzi, T. R., \& Dias, J. S. (2020). Análises da conformidade higiênico-sanitária de unidades agroindustriais familiares produtoras de derivados lácteos em municípios do Rio Grande do Sul. Redes (St. Cruz Sul, Online), Santa Cruz do Sul, 25(2), 832-856.

Oliveira, K. A, Neto J. E., Paiva J. E., \& Melo L. E. H. (2010). Qualidade microbiológica do queijo coalho comercializado no município do Cabo de Santo Agostinho, Pernambuco, Brasil. Arquivos do Instituto Biológico. 77(3), 435-440.

Oliveira, S. C. P. L., Silva, A. C., \& Carvalho, M. G. X. (2018). Diagnóstico das condições higienicossanitárias do processo de fabricação de queijo de coalho no Sertão Paraibano. Portal Regional da Biblioteca Virtual em Saúde (BVS), 2018.

Santos, C. G., Naves, E. A. A., Paiva, A. D., Vianna, P. C. B., \& Toloi, F. T. (2017). Condições Higiênico-Sanitárias na Produção de queijo artesanal produzido em Uberaba - MG. Revista do Instituto de Laticínios Cândido Tostes, 72(2), 20017. https://doi.org/10.14295/2238-6416.v72i2.594

Vinha, M. B., Pinto, C. L. O., Vanetti, M. C. D., Souza, M. R. M., Chaves, J. B. P. (2016). Qualidade de queijos Minas frescal produzidos e comercializados informalmente em agroindústrias familiares. Revista Brasileia de Agropecuária Sustentável (RBAS), 6(4), 51-60.

USDA (2019). United States Department of Agriculture. Foreign Agricultural Service. Produção brasileira de laticínios deve crescer. Brasil, 2019. 